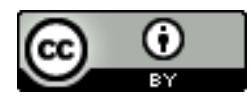

Esta obra está sob o direito de Licença Creative Commons Atribuição 4.0 Internacional.

\title{
ALFABETIZAÇÃO E LETRAMENTO: DESAFIOS DA ALFABETIZAÇÃO NA IDADE CERTA
}

Maria das Graças Sandes de Araújo ${ }^{1}$

Fernanda Santos Azevedo ${ }^{2}$

Magna Valéria dos Santos Melo ${ }^{3}$

\section{RESUMO}

O presente Artigo integra a pesquisa de mestrado intitulada "Gestão da escola pública: novos desafios para o gerenciamento dos programas federais", tendo como objetivo analisar os desafios da Alfabetização na Idade Certa e a contribuição do Programa Federal "Pacto pela Alfabetização na Idade Certa - PNAIC" para professores da escola pública que atuam do $1^{\circ}$ ao $3^{\circ}$ ano do Ensino Fundamental, considerado Ciclo da Alfabetização. Também discutir os conceitos de Alfabetização e Letramento numa perspectiva da formação continuada do professor alfabetizador.

Palavras-chave: Alfabetização, Letramento, PNAIC.

\footnotetext{
1 gsandes.sandes@gmail.com

2 nanda_azevedoo@hotmail.com

3 mayleid@hotmail.com
} 


\section{INTRODUÇÃO}

Neste Artigo relato minha experiência como Orientadora de Turma do PNAIC descrevendo, em primeiro momento, como se dinamiza nacionalmente o Programa, conceitos e historicidade da Alfabetização e do Letramento, figura do Professor e o envolvimento da equipe gestora e dos professores da rede municipal de ensino de Palmeira dos Índios no PNAIC. Tal temática advém do estudo da disciplina Alfabetização e Letramento do curso de Mestrado em Ciências da Educação, dirigida pelo professor Patrocínio Freire, e do meu interesse pelo processo vivenciado de orientação de turma de professores alfabetizadores.

Um número significativo de alunos tem chegado ao final do $3^{\circ}$ ano do EF sem saber ler e escrever com autonomia. Alguns reconhecem letras e palavras escritas com sílabas simples, mas sequer são capazes de escrever frases curtas ou ler pequenos textos.

Essa situação sempre me causou inquietação na atuação do meu trabalho na Secretaria Municipal de Educação, como Coordenadora Pedagógica. Nos encontros pedagógicos com os professores, dessas séries iniciais, sempre esteve presente o desabafo das dificuldades de aprendizagem dos alunos como assunto predominante, que não se definia, se o problema era com a forma de ensinar ou a de aprender. Observando nas capacitações dos professores das séries seguintes a reclamação em receber alunos não alfabetizados era e ainda é, uma constante. Pois bem, encontrar o caminho para alfabetizar até os 8 anos com sucesso é o maior desafio para professores alfabetizadores de todo o Brasil.

Em 2012 o Ministério da Educação lançou o Programa Nacional pela Alfabetização na Idade Certa (PNAIC), tendo como principal desafio garantir que todas as crianças brasileiras até oito anos sejam alfabetizadas plenamente. Para isso, ele contempla a participação da União, estados, municípios e instituições de todo o país.

Então em 2013, após a adesão do município ao PNAIC, tive a oportunidade de preencher os pré-requisitos exigidos para atuar como Orientadora de Estudo de turma. Daí, comecei a ser capacitada pelo Programa, e repassar para os professores a dinâmica de alfabetizar que os cadernos de estudo traziam para ser aplicados no Curso de Formação Continuada dos professores.

O objetivo, de acordo com o MEC, é formar educadores críticos, que proponham soluções criativas para os problemas enfrentados pelas crianças em processo de alfabetização. Além disso, espera-se que as escolas dialoguem com a comunidade em que se encontram inseridas, 
aprofundando a relação entre ambas e criando um espaço colaborativo, no intuito de alfabetizar todas as crianças até o final do $3^{\circ}$ ano do ciclo de alfabetização. Segundo dados do MEC, até agosto deste ano (2014), 304.736 professores foram cadastrados para os cursos de formação que serão realizados pelo Pnaic. Para isso, o Ministério da Educação (MEC), em parceria com universidades públicas federais e estaduais, além das redes de ensino municipais e estaduais, desenvolve ações formativas, materiais didáticos, monitoramento e avaliações.

Em junho de 2013, o MEC oficializou a avaliação anual e censitária para crianças que terminam o ciclo de alfabetização, do $1^{\circ}$ ao $3^{\circ}$ ano do Ensino Fundamental, em escolas públicas. A Avaliação Nacional de Alfabetização ANA, que produzirá índices sobre a aprendizagem dos alunos a respeito do sistema de escrita e ajudará no cumprimento das metas do PNAIC. Outra avaliação ligada à alfabetização é a Provinha Brasil, aplicada a alunos do $2^{\circ}$ ano do Ensino Fundamental, no início e no final do ano letivo; porém é uma prova amostral e não censitária, como a ANA.

ENTENDA A DINÂMICA DO PNAIC: APRENDER PARA ENSINAR

A metodologia do curso presencial do Pnaic propôs estudos e atividades
Para atingir a meta, o professor alfabetizador tem papel fundamental, por isso um dos eixos do Pacto é a formação continuada. No primeiro ciclo do programa, realizado de 2013 a 2014, os professores receberam formação em Língua Portuguesa. No segundo, de 2014 a 2015, em Matemática. O terceiro ciclo, de 2015 a 2016, abordou as demais áreas do conhecimento: Artes, Ciências Humanas e Ciências da Natureza.

Segundo, Mirna Araújo, coordenadora geral de formação de professores da Secretaria de Educação Básica (SEB) do MEC, para 2015, optou-se por considerar a interdisciplinaridade como a tônica do trabalho de formação. $O$ processo formativo teve como meta ampliar as discussões sobre a alfabetização na perspectiva do letramento numa abordagem interdisciplinar, que privilegie um diálogo permanente e sistemático com a prática docente e com a equipe pedagógica da escola para a garantia dos direitos de aprendizagem e desenvolvimento dos estudantes e para a melhoria da qualidade do ensino público brasileiro.

práticas, como planejamento das aulas, processo de avaliação para acompanhamento da aprendizagem e uso dos materiais didáticos e pedagógicos 
distribuídos pelo MEC. A cada turma de alfabetização, o programa distribuiu materiais como livros didáticos e respectivos manuais do professor; obras complementares aos livros didáticos $\mathrm{e}$ acervos de dicionários; obras de referência, de literatura e de pesquisa; obras de apoio pedagógico aos professores e jogos pedagógicos de apoio à alfabetização.

Nos ciclos iniciais do Programa, cada professor recebeu um kit de cadernos de Língua Portuguesa e um kit de cadernos de Matemática, abordando diferentes conteúdos relacionados à alfabetização e ao numeramento na perspectiva do letramento, além de propostas de atividades e sugestões para ampliar os estudos e os materiais distribuídos.

Segundo Telma Leal, professora da Universidade Federal de Pernambuco (UFPE) e uma das coordenadoras do material produzido pelo Pnaic, os materiais didáticos utilizados no terceiro ciclo (20152016) estabelecem um diálogo com diferentes autores em uma concepção sociointeracionista de ensino e aprendizagem. "As estratégias formativas são variadas, buscando valorizar as experiências e os conhecimentos do professor, bem como, suas experiências como leitor e produtor de textos. Outras estratégias são o reconhecimento das experiências por seus pares, que também servem como referência, a valorização do trabalho coletivo e da ação autônoma dos professores, o estímulo ao envolvimento do professor em estudo individual e coletivo. A metodologia empregada se pauta em situações que levem o professor a refletir sobre sua ação cotidiana, dialogando com os modelos teóricos que lhe servem de suporte.

$\mathrm{O}$ conteúdo dos materiais didáticos do terceiro ciclo (2015-2016) foi elaborado em parceria com 33 universidades de todo o país. Cada uma indicou seus representantes, pesquisadores de centros de pesquisa e pósgraduação, e professores da Educação Básica. Além dos autores, as universidades também indicaram leitores críticos, que fazem a análise dos cadernos.

Segundo Telma, em todos os cadernos foram inseridos relatos de professores da Educação Básica, em duas seções: na seção "Aprofundando", em que os especialistas discutem temas relativos ao ciclo de alfabetização e apresentam relatos resumidos para ilustrar ou problematizar alguma questão, e na seção "Compartilhando", que é composta por dois relatos completos de professores em cada caderno. Os relatos foram selecionados entre os apresentados pelos professores participantes da formação.

Como o tema central do terceiro ciclo (2015-2016) foi a interdisciplinaridade, os materiais para os cursos foram pensados a fim de promover a reflexão com os professores sobre o ciclo de 
alfabetização e sobre como organizar o trabalho pedagógico para integrar os diferentes campos do conhecimento. "Nossos três objetivos principais foram: refletir sobre o currículo e a ação didática, na perspectiva de integração dos componentes curriculares; auxiliar os professores a planejar a ação didática, dinamizando o uso dos materiais distribuídos pelo MEC para estimular a autonomia e atividades reflexivas de autoavaliação; e desenvolver estratégias de estudo individual e coletivo, bem como estimular práticas de planejamento individuais e coletivas", afirma a pesquisadora.

Dentre as políticas públicas educacionais o Pacto Nacional pela Alfabetização na Idade Certa (PNAIC) é o programa destacado nesta pesquisa, pela importância no enfrentamento do desafio da alfabetização. Instituído pela Portaria $\mathrm{n}^{\circ}$ 867 de 4 de julho de 2012, é um compromisso formal pelo qual o Ministério da Educação (MEC) e as secretarias de educação estaduais, municipais e distrital "reafirmam e ampliam o compromisso previsto no Decreto $\mathrm{n}^{\mathrm{o}}$ 6.094/2007, de alfabetizar as crianças até, no máximo, os oito anos de idade, aferindo resultados por exame periódico específico", considerandose que, aos oito anos de idade, as crianças precisam ter a compreensão do funcionamento do sistema de escrita, o domínio das ${ }^{1}$ correspondências grafofônicas, a fluência de leitura e o domínio de estratégias de compreensão e de produção de textos escritos, são delineados quatro princípios centrais que devem ser considerados ao longo do desenvolvimento do trabalho pedagógico:

1. o Sistema de Escrita Alfabética é complexo e exige um ensino sistemático e problematizador;

2. o desenvolvimento das capacidades de leitura e de produção de textos ocorre durante todo o processo de escolarização, mas deve ser iniciado logo no início da Educação Básica, garantindo acesso precoce a gêneros discursivos de circulação social e a situações de interação em que as crianças se reconheçam como protagonistas de suas próprias histórias;

3. os conhecimentos oriundos das diferentes áreas podem e devem ser apropriados pelas crianças, de modo que elas possam ouvir, falar, ler, escrever sobre temas diversos e agir na sociedade;

4. a ludicidade e o cuidado com as crianças são condições básicas nos processos de ensino e de aprendizagem.

Levando em consideração a concepção apresentada pelo PNAIC, percebe-se que, no campo educacional, a

\footnotetext{
1 Correspondências grafofônicas são as correspondências entre letras e fonemas. Disponível em <pacto.mec.gov.br> . Acesso em 07 junho 2015
} 
alfabetização é uma das maiores prioridades nacionais no contexto atual e que, nesse processo, o professor que atua nos anos iniciais do Ensino Fundamental precisa ter clareza do que ensinar e de como deve ensinar. Em outras palavras, é necessário que ele tenha clareza da concepção de alfabetização e letramento presente nos documentos nacionais para que esta esteja subjacente à sua prática.

De acordo com o documento elaborado pelo MEC (2012), que orienta a implementação do PNAIC, o programa constrói-se sobre quatro eixos de atuação, quais sejam:

$1^{\circ}$ - Formação continuada de professores alfabetizadores: curso presencial com duração de dois anos para os professores, ministrados pelos orientadores de estudos, educadores que fazem um curso específico, com duração total de 200 horas por ano, realizados pelas universidades públicas nacionais. $\mathrm{O}$ material para a capacitação foi desenvolvido pela Universidade de Pernambuco (UFPE) com a colaboração de 11 instituições de ensino superior. A recomendação é a de que os Orientadores de Estudo sejam selecionados entre a equipe de tutores que tiveram formação pelo Pró-Letramento no município ou no estado.

$2^{\circ} \quad$ - Materiais didáticos e pedagógicos: livros, obras complementares, dicionários, jogos de apoio à alfabetização, entre outros materiais que são disponibilizados para os professores e alunos.

$3^{\circ}$ - Avaliações: processo pelo qual o poder público e os professores acompanham a eficácia e os resultados do Pacto nas escolas participantes. Por meio dessa avaliação, poderão ser implementadas soluções corretivas para as deficiências didáticas de cada localidade. Acesse a publicação Avaliação no ciclo de alfabetização: reflexões e sugestões públicas nacionais.

$4^{\circ}$ - Gestão, controle social e mobilização: sistema de gestão e de monitoramento, com o intuito de assegurar a implementação das etapas do Pacto. $\mathrm{O}$ sistema de monitoramento (SisPacto), disponibilizado no Sistema Integrado de Monitoramento Execução e Controle (Simec), possibilita esse acompanhamento constante pelos atores envolvidos no Pacto.

\section{ALFABETIZAÇÃO E LETRAMENTO: CONCEITOS E HISTORICIDADE}

Discutiremos aqui os conceitos de alfabetização e letramento que subsidiam teoricamente o ensino da leitura e da escrita, com vistas a trazer maior clareza sobre os objetivos a serem perseguidos pela equipe diretiva e pedagógica da escola, a fim de que o aluno venha a se apropriar dessas habilidades linguísticas e socioculturais e 
tenha condições de se inserir no mundo da cultura escrita.

De acordo com Soares (1998, p.31), o termo alfabetização, significa "a ação de alfabetizar, de tornar "alfabeto", ou seja, de "tornar o indivíduo capaz de ler e escrever". Portanto, a especificidade da alfabetização está no desenvolvimento da capacidade do sujeito de se apropriar do sistema de notação alfabético da língua e de suas relações fono-ortográficas.

Mortatti (2006), em seu estudo sobre a história dos métodos de alfabetização no Brasil, afirma que:

Em nosso país, a história da alfabetização tem sua face mais visível na história dos métodos de alfabetização, em torno dos quais, especialmente desde o final do século XIX, vêm-se gerando tensas disputas relacionadas com "antigas" e "novas" explicações para um mesmo problema: a dificuldade de nossas crianças em aprender a ler e a escrever, especialmente na escola pública. Visando a enfrentar esse problema e auxiliar "os novos" a adentrarem no mundo público da cultura letrada, essas disputas em torno dos métodos de alfabetização vêm engendrando uma multiplicidade de tematizações, normatizações e concretizações, caracterizando-se como um importante aspecto dentre os muitos outros envolvidos no complexo movimento histórico de constituição da alfabetização como prática escolar e como objeto de estudo/pesquisa (p.1).

Visando a analisar a história da aprendizagem da leitura e da escrita no início do processo de escolarização, Mortatti (2006) estabelece como corte histórico o período de 1876 a 1994, dividindo-o em quatro momentos considerados por ela cruciais, quais sejam:

a metodização do ensino da leitura; a
institucionalização do método
analítico; a alfabetização sob medida e
alfabetização: construtivismo e
desmetodização Mortatti (2006)

Em 1876, data que a autora elegeu como marco inicial desse momento crucial, foi lançada em Portugal a Cartilha Maternal ou Arte da Leitura de autoria de João de Deus, a qual ficou conhecida como "método João de Deus", que passou a ser divulgado sistematicamente no Brasil por Silva Jardim, a partir da década de 1880. O “método João de Deus", também conhecido como "método da palavração", consistia em iniciar o ensino da leitura pela palavra e, a partir desta, fazer a análise dos valores fonéticos das letras. Esse primeiro momento - metodização do ensino da leitura - é marcado pela transição, no Brasil, do Império para a República, proclamada em 15 de novembro de 1889 , por marechal Deodoro da Fonseca.

De acordo com a autora, nesse período, era necessário fazer uma organização do ensino. As poucas escolas existentes na verdade eram salas adaptadas que abrigavam alunos de todas as séries e o material de que se dispunha para o ensino de leitura era precário. Geralmente iniciavase o ensino da leitura com as chamadas 
"cartas de $A B C$ " e depois os documentos manuscritos eram lidos e copiados.

Segundo (MORTATTI, 2006) o ensino de leitura nessa época pautava-se na utilização dos métodos de origem sintética, que partiam da apresentação de letras, fonemas ou sílabas até chegarem a palavras e textos. Assim, era adotada sempre uma ordem crescente de dificuldades, partindo do mais simples para o mais complexo, como por exemplo, da apresentação das letras até às sílabas, das sílabas às palavras, das palavras às frases e destas ao texto. São exemplos de métodos de origem sintética o método de soletração (alfabético), que se inicia com o nome das letras; o método fônico, que parte dos sons correspondentes às letras; e o método silábico, que inicia o trabalho com as sílabas.

Esses métodos preconizam o ensino da escrita com apoio no treino da caligrafia e da ortografia, sendo comum o trabalho com cópias e ditado. As primeiras cartilhas brasileiras, produzidas no final do século XIX, baseavam-se nos métodos sintéticos e circularam em várias províncias/estados brasileiros por muitas décadas.

Segundo a autora, esse primeiro momento se estende até 1890 "e nele tem início uma disputa entre os defensores do 'método João de Deus' e aqueles que continuavam a defender e utilizar os métodos sintéticos. Essa disputa acabou por estabelecer a tradição de que o ensino da leitura passa necessariamente pela utilização de um método.

O segundo momento - $a$ institucionalização do método analítico foi marcado pela reforma da instrução pública no estado de São Paulo que, na pretensão de servir de modelo para os demais estados, iniciou a reorganização da Escola Normal de São Paulo e a criação da Escola-Modelo Anexa. Em 1896 criou-se o Jardim da Infância nessa escola. A reforma tinha como base os novos métodos de ensino da leitura, especialmente o então novo e revolucionário método analítico que, influenciado fortemente pela pedagogia norte-americana, tinha como base “princípios didáticos derivados de uma nova concepção - de caráter biopsicofisiológico - da criança, cuja forma de apreensão do mundo era entendida como sincrética" (p. 6).

Ainda que houvesse diferentes formas de processamento do método analítico, era consenso entre seus defensores a necessidade de adaptação do ensino da leitura a essa nova concepção de criança. Assim, os métodos de origem analítica defendiam a ideia de que o ensino deveria partir de unidade de maior significado como palavras, frases ou textos, para então fazer sua análise em unidades menores, como as sílabas e fonemas. Como exemplos dessa abordagem, temos o método da palavração, que parte de palavras 
significativas para o aluno; o método da sentenciação, que parte de frases ou sentenças, e o método global, que inicia o trabalho a partir de pequenas histórias. Segundo Mortatti (2006), esse momento se estendeu até meados de 1920, e nele a disputa entre os métodos sintéticos e analíticos tornou-se acirrada.

O terceiro momento identificado por Mortatti (2006) - a alfabetização sob medida - é marcado pela "autonomia didática”. A partir de meados de 1920, houve maior resistência dos professores em relação ao método analítico que, por isso, começaram a buscar novas propostas para os problemas de ensino e aprendizagem iniciais da leitura e da escrita. Nessa busca, surge a formulação dos métodos mistos ou ecléticos (analítico-sintético ou vice-versa), fazendo com que o tom de combate e defesa acirrada ocorrida nos momentos anteriores diminuísse gradativamente, à medida que a importância do método passou a ser relativizada. Essa relativização ocorreu, principalmente, devido às novas $\mathrm{e}$ revolucionárias bases psicológicas da alfabetização disseminadas através do Livro Testes ABC para verificação da maturidade necessária ao aprendizado da leitura e escrita (1934), escrito por M. B. Lourenço Filho. Nesse livro, o autor divulga os resultados de uma pesquisa realizada com o objetivo de buscar soluções para as dificuldades de aprendizagem de leitura e escrita apresentada pelas crianças. Foram então propostas oito provas para compor os testes $\mathrm{ABC}$ e o objetivo era medir o nível de maturidade necessária ao aprendizado de leitura e escrita e classificar as crianças no intuito de formar classes homogêneas.

Com a divulgação desses resultados, os métodos de alfabetização foram relativizados e considerados tradicionais e, a partir dessa época, passaram a produzir os manuais do professor e a disseminar a ideia e a prática de um “período preparatório". De acordo com Mortatti (2006): Vai-se, assim, constituindo um ecletismo processual e conceitual em alfabetização, de acordo com o qual a alfabetização (aprendizado da leitura e escrita) envolve obrigatoriamente uma questão de 'medida', e o método de ensino se subordina ao nível de maturidade das crianças em classes homogêneas. A escrita continuou sendo entendida como uma questão de habilidade caligráfica e ortográfica, que devia ser ensinada simultaneamente à habilidade de leitura; o aprendizado de ambas demandava um "período preparatório", que consistia em exercícios de discriminação e coordenação viso-motora e auditivo-motora, posição de corpo e membros, dentre outros (p. 9).

De acordo com a autora, nesse terceiro momento que se estende até aproximadamente o final da década de 1970, a concepção de leitura e escrita descrita tem por base a alfabetização 
voltada à psicologia, preconizada em uma forma de ensino que atrelava o como ensinar subordinado à maturidade da criança a quem se ensina.

$\mathrm{O}$ quarto momento é marcado pela desmetodização do ensino de leitura e escrita. Albuquerque (apud SANTOS; MENDONÇA, 2005, p. 15) defende que, a partir da década de 1980, “[...] pesquisadores de diferentes campos Psicologia, História, Sociologia, Pedagogia etc. - tomaram como temática e objeto de estudo a leitura e seu ensino, buscando redefini-los". $\mathrm{Na}$ área da Psicologia, pesquisadoras como Emília Ferreiro e Ana Teberosky (1984) fizeram importantes contribuições a partir dos estudos sobre a psicogênese da língua escrita. Partindo do princípio de que a escrita alfabética não era um código a ser aprendido através da repetição e memorização, as autoras propuseram uma concepção de língua escrita como um sistema de notação que, no nosso caso, é alfabético. Através de seus estudos, as autoras perceberam que, para a apropriação do sistema de escrita alfabética, os alunos precisariam entender o funcionamento desse sistema, sendo fundamental a compreensão de que o que a escrita alfabética representa no papel são os sons das palavras, considerando segmentos sonoros menores que a sílaba, ou seja, os fonemas.
Esses estudos foram baseados nas teorias de Jean Piaget, um estudioso que preconiza que a criança "desenvolve sua própria maneira de aprender a ler e escrever, buscando construir seu conhecimento, através da elaboração de hipóteses e somente o produto desse conflito cognitivo permite a ela avançar frente ao sistema de escrita" (MORTATTI, 2006, p. 10).

Assim, com a difusão dos trabalhos de Ferreiro e Teberosky (1984), em sua obra Psicogênese da Língua Escrita, os métodos tradicionais passaram a ser sistematicamente questionados e introduzse, então, o pensamento construtivista no Brasil que, de acordo com Mortatti (2006), longe de se apresentar como um método novo refere-se a uma "revolução conceitual, demandando, dentre outros aspectos, abandonarem-se as teorias e práticas tradicionais, desmetodizar-se o processo de alfabetização e se questionar a necessidade das cartilhas" (ibidem, p. 10).

$\mathrm{O}$ questionamento sobre o uso de cartilha baseava-se na constatação de que tal recurso didático:

\footnotetext{
[...] aborda apenas a codificação (escrita) e a decodificação (leitura/decifração) de sinais, sem o embasamento subjacente da contribuição da linguística à formação do alfabetizador. Seu objetivo é o de fazer crianças memorizarem letras e sílabas, saberem decodificar, decifrar sinais (ler), e codificar esses sinais, transformando a fala em escrita, porém com prejuízo do significado e
} 
da produção textual espontânea (MENDONÇA, s.d, p. 34).

Notadamente, a partir dessa década há uma mudança qualitativa no enfoque sobre a aprendizagem de leitura e escrita, pois, contrariando a crença de que a alfabetização ocorreria por meio dos métodos tradicionais de ensino, difundidos pelas cartilhas, Ferreiro e Teberosky (op. cit.) defendem que é interagindo com a língua escrita, através de seus usos e funções, que essa aprendizagem aconteceria. Assim, se durante décadas a alfabetização se deu por meio do uso de cartilhas, esse material acabou perdendo sua relevância, tornando-se ineficiente para atender às novas formas de se conceber $o$ processo de alfabetização. Segundo Mortatti (2006), os questionamentos pelos quais passaram os métodos e cartilhas de alfabetização acabaram por resultar na produção de:

[...] cartilhas 'construtivistas' ou 'sócio-construtivistas' ou 'construtivistas-interacionistas'; na convivência destas com cartilhas tradicionais e, mais recentemente, com os livros de alfabetização, nas indicações oficiais e nas estantes dos professores, muitos dos quais alegam tê-las apenas para consulta quando da preparação de suas aulas; e no ensino e aprendizagem do modelo de leitura e escrita veiculado pelas cartilhas, mesmo quando os professores dizem seguir uma "linha construtivista" ou "interacionista" e seus alunos não utilizarem diretamente esse instrumento em sala de aula (MORTATTI, 2006, p.11).
Mortatti (2006) enfatiza que nesse quarto momento - alfabetização: construtivismo e desmetodização - ainda em curso, funda-se outra nova tradição pautada na desmetodização da alfabetização, que decorre da ênfase em quem aprende e o como aprende a língua escrita. A autora considera importante ressaltar, que, também na década de 1980, observa-se a emergência do pensamento interacionista em alfabetização, "que vai gradativamente ganhando destaque e gerando uma espécie de disputa entre seus defensores e os do construtivismo" (MORTATTI, 2006, p.11).

O pensamento interacionista baseiase em uma concepção que situa a linguagem como um lugar de interação humana. Nessa concepção, o texto (discurso) é a unidade de sentido da linguagem e deve ser tomado como objeto de leitura e escrita, estabelecendo-se o texto como conteúdo de ensino, que permite um processo de interlocução real entre professor e alunos descartando o uso de cartilhas para ensinar a ler e escrever.

Ainda na década de 1980, um novo termo entra em cena dando início a uma série de discussões em torno do processo de alfabetização: o letramento. Segundo Soares (1998), letramento é a versão para o Português da palavra de língua inglesa literacy e significa: 
[...] o estado ou condição de quem interage com diferentes portadores de leitura e de escrita, com as diferentes funções que a leitura e a escrita desempenham na nossa vida. Enfim: é o estado ou condição de quem se envolve nas numerosas e variadas práticas sociais de leitura e escrita (SOARES, 1998, p. 44).

De acordo com essa autora, palavras novas são criadas, outras recebem novos sentidos, quando surgem novos fatos, maneiras e ideias de compreender os fenômenos e as demandas de uma sociedade em evolução. Soares (1998) ressalta que, embora há muito se conhecesse a palavra analfabetismo, que designa o "estado ou condição de analfabeto" (ibidem, p. 19), condição do indivíduo que não sabe ler e escrever, a palavra letramento, "o estado ou condição de quem responde adequadamente às intensas demandas sociais pelo uso amplo e diferenciado da leitura e da escrita, [...] só se configurou recentemente como uma realidade em nosso contexto social" (ibidem, p. 20).

Para a autora, no conceito de letramento está implícita a ideia de que "a escrita traz consequências sociais, culturais, políticas, econômicas, cognitivas, linguísticas, quer para o grupo social em que seja introduzida, quer para o indivíduo que aprenda a usá-la" (SOARES, 1998, p. 17). A autora ainda revela haver diferentes níveis e tipos de letramento, dependendo do uso que uma dada comunidade faz da escrita para atender às demandas do contexto social e cultural. Outra autora que discute o surgimento do termo letramento é Kleiman (2008a) constatando que o conceito:

\section{[...] começou a ser usado nos meios acadêmicos como tentativa de separar os estudos sobre o 'impacto social da escrita' dos estudos sobre a alfabetização, cujas conotações destacam as competências individuais no uso e na prática da escrita (p. 15).}

A autora reforça, letramento é compreendido como um fenômeno mais amplo e que ultrapassa os domínios da escola, sendo possível "[...] definir hoje o letramento como um conjunto de práticas sociais que usam a escrita, como sistema simbólico e como tecnologia, em contextos específicos, para objetivos específicos" (op. cit.). Dessa forma, realizando um trabalho sobre os "Estudos do Letramento", que segundo a autora é "o estudo das práticas relacionadas com a escrita em toda atividade da vida social" (KLEIMAN, 2008b, p. 489), afirma:

\footnotetext{
$\mathrm{Na}$ perspectiva dos Estudos do Letramento, não há apenas uma forma de usar a língua escrita $-a$ reconhecida e legitimada pelas instituições poderosas, à qual poucos têm acesso -, mas há múltiplas formas de usá-la, em práticas diversas que são sociocultural e historicamente determinadas (KLEIMAN, 2008b, p. 490).
}

Terra (2009) também estuda o assunto, fazendo uma revisão bibliográfica e ressalta que essa palavra tem sido aplicada 
em diversas áreas do conhecimento, designando aspectos diferenciados envolvidos nas práticas da leitura e da escrita. Assim, com base no trabalho de outros autores, preconiza o uso de expressões como "letramento digital, letramento visual e letramento político", dentre outros, e defende que partindo dessa ideia, entende-se que não há apenas um tipo de letramento, mas "letramentos" (TERRA, 2009, p. 32).

\section{Essa discussão encontra} consonância em Kleiman (2008a) quando destaca:

\begin{abstract}
As práticas específicas da escola, que forneciam o parâmetro de prática social segundo a qual o letramento era definido, e segundo a qual os sujeitos eram classificados ao longo da dicotomia alfabetizado ou nãoalfabetizado, passam a ser, em função dessa definição, apenas um tipo de prática - de fato, dominante - que desenvolve alguns tipos de habilidades, mas não outros, e que determina uma forma de utilizar o conhecimento sobre a escrita (KLEIMAN, 2008a, p. 19).
\end{abstract}

Assim sendo, a autora defende que a escola, na perspectiva do letramento, utiliza apenas algumas práticas ligadas à escrita $\mathrm{e}$ seu uso, porém, fora do ambiente escolar, os indivíduos vivenciam outros usos e práticas ligados à escrita. Nesse sentido, Kleiman (2008a, p. 20) afirma que o “[...] fenômeno do letramento, então, extrapola o mundo da escrita tal qual ele é concebido pelas instituições que se encarregam de introduzir formalmente os sujeitos no mundo da escrita".

Para Tfouni (2010), o letramento deve ser compreendido como um processo sócio-histórico. Se por um lado a alfabetização está relacionada ao âmbito individual, referindo-se à aquisição da escrita enquanto aprendizagem de habilidades para leitura e escrita, geralmente adquiridas através do processo de escolarização, por outro o termo letramento está centrado nas práticas sociais de leitura e escrita e nas mudanças geradas por essas práticas em uma sociedade, quando esta se torna letrada. Segundo essa autora, o letramento:
Entre outros casos, procura estudar e descrever o que ocorre nas sociedades quando adotam um sistema de escritura de maneira restrita ou generalizada; procura ainda saber quais práticas psicossociais substituem as práticas "letradas" em sociedades ágrafas (TFOUNI, 2010, p. 12).

Percebemos dessa forma que a discussão sobre o tema é bem complexa e que não há uma única definição para o termo. Entretanto, visando atender ao objetivo exposto nessa pesquisa, nos pautaremos em Soares (1998 e 2004) para discutir o que se espera de um trabalho de alfabetização e letramento em sala de aula que permita ao estudante se inserir adequadamente no mundo letrado. 
Para Soares (2004) seria um equívoco separar a alfabetização do letramento, pois a entrada tanto das crianças como dos adultos analfabetos no mundo da escrita acontece "pela aquisição do sistema convencional de escrita - a alfabetização e pelo desenvolvimento de habilidades de uso desse sistema em atividades de leitura e escrita, nas práticas sociais que envolvem a língua escrita - o letramento" (op. cit., p. 14). Assim a autora defende que alfabetização e letramento são processos interdependentes e indissociáveis, pois a alfabetização se desenvolve através de práticas sociais de leitura e escrita, ou seja, a partir de atividades de letramento, e este, por sua vez, só se desenvolve através da alfabetização, ou seja, da aprendizagem das relações entre grafemas e fonemas. Dessa forma argumenta que, enquanto na concepção "tradicional" de alfabetização os dois processos eram independentes, sendo que a alfabetização precedia o letramento, na concepção atual os dois processos são simultâneos.

A partir dessa discussão, Soares (2004) ressalta que diante dos precários resultados obtidos na aprendizagem inicial da língua escrita, torna-se necessário:

[...] rever os quadros referenciais e os processos de ensino que têm predominado em nossas salas de aula, e talvez reconhecer a possibilidade e mesmo a necessidade de estabelecer a distinção entre o que mais propriamente se denomina letramento, de que são muitas as facetas [...] e o que é propriamente a alfabetização, de que também são muitas as facetas (p. 15).

Segundo essa autora, a partir desse reconhecimento é indispensável “promover a conciliação entre essas duas dimensões da aprendizagem da língua escrita, integrando alfabetização e letramento, sem perder, porém, a especificidade de cada um desses processos" (op. cit., p. 15). Dessa forma Soares alega:

[...] precisaríamos de um verbo "letrar" para nomear a ação de levar os indivíduos ao letramento... Assim, teríamos de alfabetizar e letrar como duas ações distintas, mas não inseparáveis, ao contrário: o ideal seria alfabetizar letrando, ou seja: ensinar a ler e a escrever no contexto das práticas sociais da leitura e da escrita, de modo que o indivíduo se tornasse, ao mesmo tempo, alfabetizado e letrado (SOARES, 1998, p. 47).

(BRASIL, 2007a, p. 70) nos apresenta que cabe, então, à instituição escolar, responsável pelo ensino da leitura e da escrita, ampliar as experiências das crianças e dos adolescentes de modo que eles possam ler e produzir diferentes textos com autonomia. Para isso, é importante que, desde a educação infantil, a escola também se preocupe com o desenvolvimento dos conhecimentos relativos à aprendizagem da escrita alfabética, assim como daqueles 
ligados ao uso e à produção da linguagem escrita.

Ainda defende que as crianças possam vivenciar, desde cedo, atividades que as levem a pensar sobre as características do nosso sistema de escrita, de forma reflexiva, lúdica, inseridas em atividades de leitura e escrita de diferentes textos. É importante considerar, no entanto, que a apropriação da escrita alfabética não significa que o sujeito esteja alfabetizado. Essa é uma aprendizagem fundamental, mas para que os indivíduos possam ler e produzir textos com autonomia é necessário que eles consolidem as correspondências grafofônicas, ao mesmo tempo em que vivenciem atividades de leitura e produção de textos. (p. 22).

Concordamos com Soares em sua discussão e entendemos que a abordagem tradicional de alfabetização, em que primeiro se aprende a "decifrar um código" para só depois ler efetivamente, não tem dado conta da formação de leitores/escritores, haja vista que essa formação passa pelo desenvolvimento de práticas discursivas de construção de sentido, ou seja, é necessário que o aluno entenda porque, como e com quais interesses os textos funcionam, e se coloquem criticamente frente aos mesmos. Por outro lado, não basta também apresentar um conjunto de textos que circulam na sociedade para se garantir que os alunos se apropriem da escrita alfabética, pois, como destacado anteriormente, esta aprendizagem não ocorre de maneira espontânea, pelo contrário, requer que o aluno reflita sobre as características do sistema de escrita.

Se há uma função primordial da escola, certamente ela passa pela formação de cidadãos leitores e escritores competentes. Esta formação requer a interação com diferentes textos orais e escritos em diferentes situações comunicativas. Portanto, nessa nova perspectiva, o desafio é desenvolver um trabalho escolar que garanta ao aluno a apropriação do sistema de escrita alfabético e lhe permita a inserção nas práticas sociais de leitura e escrita.

Para além dos métodos tradicionais de ensino, é imprescindível que o aluno tenha contato com diferentes textos orais e escritos em circulação social e para tal a escola deve propor atividades que contemplem essa diversidade textual, de forma que os educandos possam construir conhecimentos e ter condições de participar ativamente na sociedade. Para tanto, o professor deverá lançar mão de uma série de ferramentas educacionais que possibilitem ao aluno o contato direto com o objeto de estudo, de forma que aprenda a ler e escrever, e para que essa aprendizagem se traduza em práticas conscientes na sociedade. 


\section{ALFABETIZAR E LETRAR - A FIGURA DO PROFESSOR EM FORMAÇÃO}

O ser professor é uma expressão que diz respeito principalmente aos aspectos que se relacionam à pessoa que ensina: a história do professor, suas memórias, o seu engajamento, sua socialização com os outros, seus problemas: escolas com dificuldades diversas, formação inicial precária, salários baixos, entre outros (FERREIRA apud BRASIL, 2012c, p. 15).

Ainda segundo a autora, é sempre bom lembrar que o professor é uma pessoa, e como tal, possui emoções, vivências e experiências que nem sempre têm sido respeitadas ao longo da história do Brasil. Junte-se a isso o fato de, muitas vezes, o fracasso escolar brasileiro ser relacionado à baixa qualidade do trabalho do professor. Portanto, para ser professor é preciso "construir representações sobre a atividade profissional e desconstruir a imagem negativa imposta aos profissionais da educação" (ibidem, p. 16). Assim sendo, o curso de formação continuada deve “investir na construção positiva da identidade profissional coletiva, reforçando a importância e a responsabilidade dessa atividade no contexto social" (ibidem, p. 16). Para tanto, deve-se olhar para o professor de forma individual, como sujeito de sua própria história proporcionando ao docente a oportunidade de revisitar suas experiências profissionais e de formação e analisar sua atuação no momento atual. A autora acredita que a utilização das experiências trazidas pelos professores pode ser útil na medida em que há um resgate de suas práticas e de seu fazer pedagógico.

A socialização: Nesse item é reforçada a ideia de que o professor deve ser estimulado a trabalhar, comunicando-se por meio de atividades em grupo, o que colabora para o exercício de troca de turno entre os pares, exercita a argumentação e, principalmente a intervenção junto aos colegas e alunos. A autora acredita que “esse exercício pode contribuir tanto para o desenvolvimento profissional como pessoal" (ibidem, p. 17).

O engajamento: Segundo Ferreira (apud Brasil, 2012c), o prazer em continuar aprendendo e descobrindo coisas novas auxilia no engajamento profissional docente nas formações na prática cotidiana, sendo necessário que o curso de formação continuada provoque o professor com desafios diversos e questionamentos e, ao mesmo tempo, valorize o conhecimento e o saber que ele traz.

A colaboração: Finalmente, nesse item a autora ressalta a importância de um trabalho que venha romper com o individualismo e ter como base um aprendizado coletivo, pautado na colaboração, de forma que os professores 
possam exercitar "a participação, o respeito, a solidariedade, a apropriação e $\mathrm{o}$ pertencimento" (ibidem, p. 19).

Diante desses aspectos que fundamentam o curso de formação continuada, a autora enfatiza:

Se considerarmos, de fato, que o professor é ativo em sua própria profissionalização e é capaz de construir saberes cotidianamente, refletindo sobre sua própria trajetória e articulando saberes diversos, então é necessário ouvir o que eles próprios dizem sobre formação continuada. [...] A partir da escuta dos sujeitos envolvidos no início, no meio e no final decada etapa de formação, podese planejar e replanejar os próximos encontros e os programas de formação, tendo como perspectiva as necessidades e desejos dos professores. (FERREIRA apud BRASIL, 2012c, p. 19)

Esses são os princípios apontados e perseguidos pelo PNAIC, que encara o professor como figura central no processo ensino/aprendizagem, ao adotar uma metodologia no curso de formação continuada pautada na prática da reflexividade, que aprimora de maneira constante a prática pedagógica do professor, a partir de experiências compartilhadas, de reflexões sobre trabalhos desenvolvidos e do aprendizado de escolhas didáticas que garantam o aprendizado do aluno.

O professor precisa estar motivado a participar do curso de formação continuada, estudar os materiais que são direcionados para ele, entender, analisar e buscar transformar e/ou ressignificar sua prática pedagógica para que o programa realmente possa alcançar o resultado almejado. Nesta tarefa entram como coadjuvante a gestão da escola e seu planejamento pedagógico de apoio à extensão dos cursos para a prática de sala.

A discussão sobre alfabetização e letramento aqui apresentada está em consonância com as concepções defendidas tanto pelo documento de orientações oficiais, produzido pelo MEC, que organiza a nova estrutura do EF, intitulado "Ensino Fundamental de Nove Anos: orientações para inclusão das crianças de seis anos de idade”, quanto pelo Caderno de Formação de professores alfabetizadores do Pacto Nacional pela Alfabetização na Idade Certa, denominado "Currículo na Alfabetização: Concepções e Princípios”.

Partindo da concepção interacionista da linguagem, os dois documentos preconizam que para se reduzirem as diferenças sociais, a escola precisa assegurar a todos os estudantes diariamente - a vivência de práticas reais de leitura e produção de textos escritos e orais diversificados. Para isso, a instituição escolar deve ampliar as experiências que as crianças trazem do convívio familiar em diferentes contextos, visando à autonomia dessas crianças na leitura e produção de diferentes textos, considerando a compreensão dos aspectos fonoortográficos para a compreensão do sistema 
alfabético. A proposta pedagógica defendida pelo Pacto Nacional pela Alfabetização na Idade Certa traz a mesma discussão.

\section{ENVOLVIMENTO DA EQUIPE GESTORA E DOS PROFESSORES}

Defendemos que a forma de a gestão da escola promover uma ação integrada com o Pacto para a apropriação e aprofundamento dos conteúdos discutidos pelo programa é incentivar grupos de estudos na própria escola, para que os materiais disponibilizados sejam totalmente aproveitados. Assim sendo, torna-se importante a organização de tempo e espaço para estudo dos professores e coordenação pedagógica. O material do Pacto é muito rico e necessita de tempo maior para apropriação e reflexão. Ao estudarem e planejarem juntos o trabalho pedagógico teve a oportunidade de melhor gerenciarem o programa na escola. A subseção seguinte tem o objetivo de sugerir a organização do tempo e do espaço para que as atividades de estudo e planejamento aconteçam de forma sistemática na escola.

No intuito de que as ações promovidas pelo programa venham efetivamente alcançar os resultados, o documento de apresentação do PNAIC, cujo objetivo é “organizar boas estratégias de gestão que contribuam para melhorar a qualidade do ensino nos anos iniciais de escolarização" (Brasil, 2012d, p. 9), recomenda a constituição de equipes de trabalho com a tarefa específica de "planejar, monitorar e realizar ações no âmbito do ciclo de alfabetização em duas instâncias: equipe na secretaria de educação, ligada ao grupo de gestão central; equipes nas escolas" (BRASIL, 2012d, p.9).

Denomina-se “equipe de gestão central" a que atua na gestão da secretaria, não estando, portanto, centrada em uma escola específica. Em alguns sistemas é denominada como equipe técnica, diretores de projetos, dentre outros (BRASIL, 2012c). O grupo de gestão central deve exercer o papel de definir os princípios gerais e construir as orientações globais de trabalho sendo um articulador entre as unidades escolares. Quanto às equipes escolares, essas devem "definir planos de ação por unidade escolar e coordenar o trabalho coletivo, no universo dessas unidades" (ibidem, p.9).

De acordo com o mesmo documento, a equipe ligada à gestão central deve ser formada por um grupo de profissionais de áreas diversas, como pedagogos, psicólogos e outros, voltado a "refletir e conduzir ações específicas, voltadas para garantir a alfabetização das crianças [...]" (ibidem, p. 9). Assim, o ponto de partida de trabalho dessa equipe deve ser a promoção de ações voltadas à construção e/ou reformulação de propostas curriculares 
se necessário, e implementação das mesmas, ou seja, um dos papéis dessa equipe é "planejar ações voltadas à discussão permanente da proposta curricular, procedendo às reformulações sempre que isso se fizer necessário" (ibidem, p. 9). Além disso, tendo por base a proposta curricular, esse grupo teria a responsabilidade de "planejar ações de formação continuada e diretrizes gerais para o funcionamento das equipes das escolas, envolvendo ativamente os docentes e coordenadores pedagógicos" (ibidem, p. 9). Assim as dimensões da formação continuada e da prática de ensino ficariam mais articuladas.

Outro ponto de destaque nesse documento é que as ações de avaliação da rede de ensino sejam planejadas de forma a permitir verificar se as ações previstas no plano de ação da equipe estão sendo realizadas, tornando-se imprescindível que a equipe central, em parceria com os professores, elaborem instrumentos de avaliação que "contemplem os conhecimentos, habilidades e capacidades que são direitos de aprendizagem das crianças de cada etapa de escolarização, previstos no documento curricular" (ibidem, p.10).

Quanto às equipes das escolas, essas devem ser formadas pelo "diretor, vicediretor, secretários, coordenadores pedagógicos, bibliotecários, mediadores de leitura, professores, especialistas para atendimento das crianças com necessidades educacionais especiais, dentre outros [...]" (BRASIL, 2012d, p. 10). Sua função é planejar o trabalho escolar voltado para a execução de ações relativas ao ciclo de alfabetização.

Outra recomendação diz respeito aos professores que trabalham nos três anos iniciais do EF. De acordo com o documento de apresentação do PNAIC, nesses três anos iniciais devem ser mantidos professores efetivos, com experiência na docência e conhecimentos relativos aos processos de ensino/aprendizagem de leitura e escrita. Além disso, o documento apresenta a seguinte reflexão:

\begin{abstract}
A continuidade dos trabalhos durante estes três primeiros anos é uma das formas de garantir condições mais seguras de planejamentos em longo prazo, sobretudo para lidar com as aprendizagens mais complexas. Deste modo, manter os mesmos professores durante todo o ciclo de alfabetização é uma boa estratégia de organização do trabalho dos docentes nestes anos de ensino. (BRASIL, 2012d, p.12)
\end{abstract}

Em relação às unidades escolares, uma das sugestões apresentada no documento de apresentação do PNAIC é que a escola construa seu Projeto Político Pedagógico, organize cronogramas de trabalho e defina a dinâmica do trabalho coletivo, de forma a contemplar encontros de estudo, de planejamento didático, de 
acompanhamento e de avaliação (da escola e das crianças) nos processos de ensino.

Além disso, há uma recomendação a respeito do papel a ser exercido pelo coordenador pedagógico, que, dentre outras funções, deve atuar pesquisando e integrando às ações da escola os projetos culturais da comunidade, de forma que o contexto escolar possa ser aproximado ao contexto extraescolar do qual as crianças participam.

Aos diretores, o documento propõe:

Cabe aos diretores, coordenadores pedagógicos e professores estabelecerem relações favoráveis com as famílias, acatando suas contribuições e fornecendo as informações e orientações que as ajudem a participar efetivamente da vida escolar das crianças (BRASIL, 2012d, p.13).

Desta forma, é essencial o papel do gestor como articulador desse programa na escola. Se o diretor não abraçar esse programa, nós não vamos conseguir avançar em nada. Embora o professor participe, temos a consciência de que, por mais mobilização que façamos, nem todos ainda acreditam no programa, ou as pessoas, por seus motivos diversos, não podem participar. Então, se o diretor abraça a causa, se ele entende essa proposta, ele tende a fazer a ponte com o que hoje acontece na escola pra tentar motivar os outros que por algum motivo não participam, para que tenham sucesso em
$100 \%$ dos alunos. É o sucesso do aluno, o sucesso do professor e da escola como um todo.

O Ministério da Educação, ou as próprias secretarias, deveriam pensar em programas como esses em termos da escola/instituição, mobilizando os gestores, coordenadores pedagógicos e professores, que se envolvam continuamente em discussões em prol da alfabetização. Assim, o coordenador aponta a necessidade de preparação da coordenação pedagógica, ressaltando que, embora o MEC não reconheça isso como uma falha, ela entende que em um programa de formação de professores, os coordenadores pedagógicos deveriam estar incluídos. Sobre esse ponto a coordenadora reflete:

\footnotetext{
Como é que ele vai coordenar alguém que sabe mais do que ele, que está estudando mais do que ele? [...] Então, caberia à Secretaria de Educação, organizar grupos de estudos com esses coordenadores para estudar o material do Pacto que está disponível, não tem que comprar, não tem que gastar, está no site, é só baixar. (Coordenadora Geral, entrevista 24/04/14)
}

Finalmente, a coordenadora geral aponta o Pacto como um programa muito bem articulado defendendo a necessidade do máximo aproveitamento do mesmo de forma a alcançar os resultados almejados. Acredita que, mesmo não sendo possível mudar totalmente a realidade, 
num curto período de tempo, seria possível conseguir mudanças mais concretas se o programa fosse contínuo e se seguisse o fluxo da

\section{METODOLOGIA}

Trata-se de uma revisão de literatura tradicional, não sistemática, descritiva, de natureza qualitativa e bibliográfica, já que a

\section{CONCLUSÃO}

Nestes dois anos de experiência como coordenadora do Pnaic, observei claramente a transformação de muitos professores em sala de aula. Com a evolução dos encontros de formação, os docentes perceberam que o Pnaic tinha algo novo a oferecer e mergulharam no projeto, colocando em prática os conteúdos e as estratégias que aprendiam nos encontros. Antes do Pnaic, muitos professores não sabiam elaborar nem desenvolver uma sequência didática de aulas, o que muito praticaram nas formações.

O programa possibilitou a renovação de práticas pedagógicas em sala de aula e o desenvolvimento de atividades diferenciadas de letramento. O Pnaic reavivou o debate sobre a alfabetização nos anos iniciais, que são a base da vida acadêmica dos alunos. Com o programa, os professores poderam ampliar seus conhecimentos sobre a prática de escola, independente de férias do MEC, de férias da universidade ou de calendário orçamentário.

análise se realizou em diversas fontes de pesquisas como conteúdo de livros, artigos científicos, sites, dissertações, teses e bibliográficas virtuais.

alfabetização e melhorarem a atuação em sala de aula, percebendo se o planejamento e as intervenções eram apropriados às dificuldades dos alunos. Isso me fez perceber que eu tinha muito o que aprender com eles e para eles, e que meu papel de orientadora de estudo, não foi apenas mediar o estudo, mas ter uma apreciação crítica sobre o meu trabalho e o desenvolvimento dos professores alfabetizadores.

Além dos cursos presenciais, os participantes destacaram a qualidade e o conteúdo dos materiais pedagógicos. Tanto a formação como os materiais influenciaram muito o ensino em sala de aula, pois são muito ricos e práticos. Já as aulas se tornaram mais lúdicas, criativas e reflexivas. Sinto que o programa desacomodou e despertou nos professores algo que estava adormecido. Além das mudanças em sala de aula, os encontros de formação ofereceram subsídios para que as 
escolas e os educadores desenvolvessem projetos. Vários projetos foram realizados a partir do Pnaic nas escolas do município, em que os professores produziram materiais como jogos de leitura, maquetes, cartazes e outros.

O conteúdo da formação inclui textos que abordam a diversidade linguística, a educação do campo, a educação inclusiva, as diferentes infâncias, entre outros aspectos, que ajudaram a entender a complexidade sociocultural de nosso país. A proposta de formação não é fechada, de modo que cada universidade e cada município tem espaço para inserir temáticas específicas da região, bem como adaptar experiências de outras localidades de acordo com sua própria realidade. Durante a formação, tivemos o estudo da educação do campo, que foi realizado com

\section{REFERÊNCIAS}

ALMEIDA, Fernando José de. Progressão continuada não é aprovação automática. NOVA ESCOLA GESTÃO ESCOLAR, Edição 238, dezembro 2010. Disponível em:

$<$ http://revistaescola.abril.com.br/gestaoescolar/diretor/progressao-continuada-naoaprovacao-automatica-611988.shtml>.

\footnotetext{
BARROSO, T. Concepções epistemológicas de alfabetização: a perspectiva (sócio) interacionista. Juiz de Fora: Universidade Federal de Juiz de Fora/Faced/Pedagogia/UAB, 2008. Circulação interna.
}

professores alfabetizadores das zonas rural e urbana. Ocorreu uma troca de experiências e saberes e, simultaneamente, aprendemos como adaptar uma atividade à pratica social e educacional conforme a realidade de nossos alunos.

Mas ainda são muitos os desafios e dificuldades encontradas pelos educadores, como o excesso de alunos em sala de aula e o tempo escasso para a execução das atividades e dos cursos de formação. A maior dificuldade é o pouco tempo para a formação presencial, já que os encontros ocorrem aos sábados, quando os professores estão muito cansados e têm trabalhos de planejamento para realizar em casa. Uma solução seria realizar os encontros de formação dentro do horário de trabalho do professor.

BEAUCHAMP, Jeanete; PAGEL, Sandra D.; NASCIMENTO, Aricélia R. do. (Org.). Ensino Fundamental de nove anos: orientações para a inclusão da criança de seis anos de idade. Brasília: MEC: SEB, 2007.

BRASIL. Lei $n^{\circ}$ 9.394, de 20 de dezembro de 1996. Estabelece as diretrizes e bases da educação nacional. Diário Oficial da União, Poder Executivo. Brasília, CF, 23 dez. 1996.

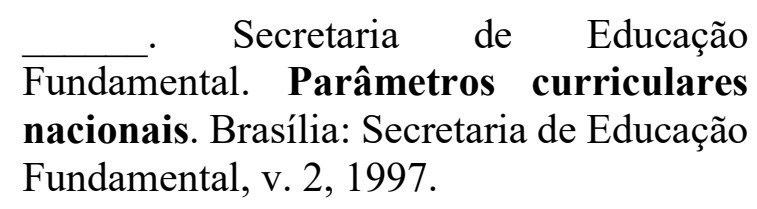


. Ministério da Educação (MEC).

Ensino Fundamental de nove anos Orientações Gerais. Brasília, DF, 2004.

. Ministério da Educação. Conselho Nacional de Educação. Câmara de Educação Básica. Parecer $n^{\circ} 18$, de 15 de setembro de 2005. Diário Oficial da União, Brasília, DF, 7 out. 2005. Disponível em: $<$ http://portal.mec.gov.br/cne/arquivos/pdf/ pceb018_05.pdf>.

. Ministério da Educação. Secretaria de Educação Básica. Ensino Fundamental de Nove Anos: orientações para a inclusão da criança de seis anos de idade. Brasília, DF, 2007a. Disponível em: $<$ http://portal.mec.gov.br/seb/arquivos/pdf/ Ensfund/ensifund9anobasefinal.pdf $>$.

. Ministério da Educação. Decreto $\overline{\mathbf{n}^{\mathbf{0}}} \mathbf{6 . 0 9 4 / 2 0 0 7}$. Dispõe sobre a implementação do Plano de Metas Compromisso Todos pela Educação, pela União Federal, em regime de colaboração com Municípios, Distrito Federal e Estados, e a participação das famílias e da comunidade, mediante programas e ações de assistência técnica e financeira, visando a mobilização social pela melhoria da qualidade da educação básica. Brasília, DF, 2007b. Disponível em: $<$ http://www.planalto.gov.br/ccivil_03/_ato 2007-2010/2007/decreto/d6094.htm>.

\section{. Resolução CNE/CEB n ${ }^{0}$ 7/2010.}

Fixa as Diretrizes Curriculares Nacionais para o Ensino Fundamental de 9 (nove) anos.

. Ministério da Educação. Portaria $n^{\circ}$ $\overline{867 / 2012}$. Institui o Pacto Nacional pela Alfabetização na Idade Certa e as ações do Pacto e define suas diretrizes gerais. Diário Oficial da União, Brasília, DF, 4 jul. 2012a. Disponível em: $<$ http://pacto.mec.gov.br/images/pdf/port 867_040712.pdf $>$.
Ministério da Educação. Secretaria de Educação Básica. Diretoria de Apoio à Gestão Educacional. Pacto Nacional pela Alfabetização na Idade Certa. Currículo na Alfabetização: Concepções e Princípios. Brasília: MEC: SEB, 2012b. Disponível em:

$<$ http://pacto.mec.gov.br/images/pdf/Form acao/Ano_1_Unidade_1_MIOLO.pdf $>$.

- Secretaria de Educação Básica. Diretoria de Apoio à Gestão Educacional. Pacto nacional pela alfabetização na idade certa: formação de professores no pacto nacional pela alfabetização na idade certa/Ministério da Educação, Secretaria de Educação Básica, Diretoria de Apoio à Gestão Educacional. Brasília: MEC, SEB, 2012c. Disponível em: $<$ http://pacto.mec.gov.br/images/pdf/Form acao/Formacao_de_professores_MIOLO.p df $>$.

Secretaria de Educação Básica. Diretoria de Apoio à Gestão Educacional. Pacto nacional pela alfabetização na idade certa: formação do professor alfabetizador: caderno de apresentação/Ministério da Educação, Secretaria de Educação Básica, Diretoria de Apoio à Gestão Educacional. Brasília: MEC, SEB, 2012d. Disponível em: $<$ http://pacto.mec.gov.br/images/pdf/Form acao/Apresentacao\%20MIOLO.pdf $>$.

. Ministério da Educação. Secretaria Executiva. Avaliação Nacional da Alfabetização - ANA. Documento Básico. Brasília, DF, 2013. Disponível em: $<$ http://download.inep.gov.br/educacao_ba sica/saeb/2013/livreto_ANA_online.pdf $>$.

FERREIRA, Andrea. T. B. e LEAL, Telma F. A formação continuada de professores: enfim o que pensam e sugerem os docentes? In Formação continuada de professores: Reflexões sobre a prática. Recife: Editora Universitária, UFPE, 2010. 
KLEIMAN, Angela B. (Org.). Os significados do letramento: uma nova perspectiva sobre a prática social da escrita. Campinas: Mercado das Letras, 2008a.

MENDONÇA, Onaide Schwartz. Percurso Histórico dos Métodos de Alfabetização. Faculdade de Ciências e Tecnologia Departamento de Educação.UNESP/ Presidente Prudente. Disponível em: http://www.acervodigital.unesp.br/bitstrea $\underline{\mathrm{m} / 123456789 / 40137 / 1 / 01 \mathrm{~d} 16 \mathrm{t} 02 . \mathrm{pdf}}$
MORTATTI, Maria do Rosário L. História dos métodos de alfabetização no Brasil. $2006 . \quad$ Disponível em: $<$ http://www.idadecerta.seduc.ce.gov.br/do wnloadlencontro_paic_ceu_24_2602_2010 Vhistorias_do_metodos_de_alfabetizacao_b rasil.pdf $>$.

TFOUNI, Leda VerdianiTfouni. Letramento e alfabetização. 9 ed. São Paulo: Cortez, 2010. 